\title{
Neuroinflammation in Epilepsy—Diagnostics and Therapeutic Perspectives
}

\author{
Piotr Lach $^{1} \cdot$ Wiktoria Klus $^{1} \cdot$ Krystian Zajdel $^{1} \cdot$ Adam Szeleszczuk $^{1} \cdot$ Ewelina Komorowska $^{1} \cdot$ Klaudia Burda $^{1}$. \\ Przemysław Kurowski ${ }^{2,3}$ (1)
}

Accepted: 30 November 2021 / Published online: 8 December 2021

(c) The Author(s) 2021

\begin{abstract}
Epilepsy is a neurological disease that affects approximately $1 \%$ of the world's population. Epilepsy is characterized by the occurrence of repeated epileptic seizures due to abnormal neuronal activity. Although this disorder is currently incurable, it can be controlled for years with the appropriate therapy and patient adherence. Inflammation is an organism's natural response to a pathological stimulus, aimed at eliminating the triggering factor. Multiple studies point out a significant correlation between an increased level of inflammatory mediators and the frequency of epileptic seizures. Increased levels of IL-1 $\beta$, IL-2, IL-4, IL-6, IFN- $\gamma$, and TNF- $\alpha$ were found in the serum of patients with epilepsy. Additionally, pro-inflammatory cytokines were found to be upregulated during epileptic activity in rodents: CCL2 and CCR2 receptor expression was shown to be upregulated during inflammation induced by lipopolysaccharide administration, and CXCR5 was found to be primarily upregulated in brain cells. Early detection of the described factors may serve as a biomarker for epilepsy but also hold potential in developing novel immunomodulating therapies. Thus, a better understanding of the immune system's involvement is necessary for the development of new therapeutic perspectives in epilepsy.
\end{abstract}

Keywords Inflammation $\cdot$ Cytokines $\cdot$ Epilepsy $\cdot$ Seizures $\cdot$ Pharmacology

\section{Introduction}

Epilepsy is commonly understood to refer to a group of chronic neuronal disorders having a complex and multifactorial background, characterized by recurrent seizures [1]. Cognitive deficits and mood disorders often accompany epileptic seizures [2]. Epilepsy is a brain dysfunction with

This article is part of the Topical Collection on

Neuropharmacology

Przemysław Kurowski

przemyslaw.kurowski@gmail.com;

przemyslaw.kurowski@wum.edu.pl

1 Students Research Circle Cerebrum at the Department of Pharmacodynamics, Faculty of Pharmacy, Medical University of Warsaw, Warsaw, Poland

2 Department of Pharmacodynamics, Faculty of Pharmacy, Medical University of Warsaw, Warsaw, Poland

3 Laboratory of Physiology and Pathophysiology, Department of Pharmacodynamics, Centre for Preclinical Research and Technology, Medical University of Warsaw, Banacha 1B, 02-097 Warsaw, Poland a paroxysmal character. Spontaneous attacks are triggered by erroneous synchronous discharges of neurons, which manifest themselves as loss of consciousness, tonic muscle contraction, and sensory and vegetative disorders [3]. A wide range of antiepileptic drugs (AEDs) have been used to treat patients with epilepsy. However, about one-third of individuals with epilepsy still experience seizures that do not respond to medication [4]. Therefore, understanding the cellular mechanisms involved in epileptogenesis is necessary for the development of new drugs that may be useful in treating epilepsy.

\section{Epilepsy}

The appearance of epileptic seizures is related to the sum of the ensuing neuronal discharges that result from prolonged bursts of action potentials, followed by neuronal hyperpolarization [5, 6]. Symptoms of an epileptic seizure depend on the brain region of the attack. They arise in certain areas of the brain and can then spread to the cerebral hemispheres or remain in the place of origin. The mechanism underlying 
formation of the epileptic focus is still not fully understood. Most likely it is associated with mutation in the genes encoding voltage-dependent subunits of sodium channels; as a result, glutamatergic neurons become overactive and glutamate is released in excess or fails to be inhibited by gamma-aminobutyric acid (GABA) [7]. Recent studies have shown that the brain tissue of patients with epilepsy, before or during an attack, contains elevated glutamate concentrations, especially at the epileptic focus itself. This increase may also be due to a failure in glutamate uptake, as well as glutamate-dependent changes in receptor function [8]. An increase in glutamate binding by NMDA receptors has been demonstrated in patients with epilepsy, leading to a sodium and calcium influx into the neuronal cell $[9,10]$.

Epilepsy treatment is based on blocking pre- and postsynaptic sodium channels through antiseizure drugs, thus reducing the activity of the epileptic seizure and reducing the chance of its spread [11]. Nevertheless, a significant group of epilepsy patients still do not respond to the drugs currently in use. It should also be noted that current medications only reduce the intensity of epileptic seizures. Despite continuous pharmacological developments and currently available surgical treatments, limited by an insufficient understanding of the mechanisms underlying the development of epilepsy, some patients still remain symptomatic even with optimal available therapies [12].

During the discharges that stimulate glutamatergic neurons under physiological conditions, inhibitory interneurons are also activated. GABA binds to the ionotropic $\mathrm{GABA}_{\mathrm{A}}$ and metabotropic $\mathrm{GABA}_{\mathrm{B}}$ receptors. Activation of $\mathrm{GABA}_{\mathrm{A}}$ receptors leads to $\mathrm{Cl}^{-}$anions entering the neuronal cell, leading to hyperpolarization or preventing depolarization of the neuron. Several studies suggest that mutations in the $\alpha 1$ and $\gamma 2$ subunits of the $\mathrm{GABA}_{\mathrm{A}}$ receptor underlie the development of idiopathic epilepsy $[13,14]$. These mutations lead to disturbances in ion permeability and receptor transport on the cell surface. The basic mechanism of antiepileptic treatment is restoration of inhibition mediated by GABA [15]. Barbiturates and benzodiazepines that bind to the $\mathrm{GABA}_{\mathrm{A}}$ receptor increase the effect of endogenous GABA, which leads to an increase in the opening time and the frequency of opening of the chloride channel [16]. Many AEDs increase the concentration of endogenous GABA, including modulating the action of GAD glutamate decarboxylase - an enzyme critical to GABA synthesis-which also leads to increased availability of this neurotransmitter [17]. On the other hand, the inhibition of GABA aminotransferase, which is responsible for catalyzing the decomposition of GABA, leads to its accumulation, which also reduces epileptic symptoms [18].

The occurrence of mutations in voltage-dependent sodium channels and increased binding of glutamate by AMPA and NMDA receptors induces hyperactivity of glutamatergic neurons leading to the release of excess glutamate
[19]. In these neuronal cells, decreased glutamate reuptake has also been observed, and the resulting accumulation of neurotransmitter increases the sensitivity of AMPA and NMDA receptors. At the same time, hyperactive neurons activate GABAergic inhibitory interneurons, which, due to the GABA receptor mutation, fail to inhibit hyperactive neurons [15]. Together, these phenomena lead to a wave of excessive excitation between neuronal cells.

\section{Neuroinflammation in Epilepsy}

Recent studies have confirmed that epilepsy may have not only a neuronal but also a non-neuronal pathogenesis, e.g., glial cells or brain vascularization [20,21]. Glial functions that are regulated unpredictably can trigger an attack and thus promote epileptogenesis, a mechanism based on increasing neuronal excitability and inflammatory processes. Various glial abnormalities, including chronically activated astrocytes or microglia, glial scars, and a variety of gliomas, often form epileptic centers in the brain [22]. The central nervous system (CNS) shows a strong inflammatory response not only upon exposure to infectious agents such as LPS- or TLR receptors but also in the case of injuries such as epileptic seizures. The outcome of inflammation on cells depends mainly on the amounts of cytokines produced and the length of time the tissue is exposed to them and the balance between neurotrophic factors and inflammatory factors produced by the cells responsible for them [23].

Changes in the structure of the blood-brain barrier (BBB) can be caused by trauma, seizures, or infections in the CNS [24]. Many neurological diseases share the common trait of inflammation and a weakening of the integrity of the BBB [25]. The resulting exogenous inflammatory mediators have the ability to reduce the threshold for epileptic seizures, thereby altering the sensitivity of the channels, the uptake or release of neurotransmitter, and the glia-related regulation of extracellular ion concentration [26, 27].

There is a multitude of evidence that epilepsy is associated with inflammation and with increased levels of proinflammatory cytokines in neural tissues, the cerebrospinal fluid, and blood plasma. The concentration of cytokines in the cerebrospinal fluid of patients with epilepsy correlates with both frequency and duration of seizures [28]. Simultaneously, the inflammatory reactions in the brain can lead to BBB damage, causing an influx of albumin from the blood to the brain, increasing the production of cytokines and inhibiting the reabsorption of glutamate and potassium ions, which leads to neuronal hyperactivity [22]. Together with albumin leakage, leukocyte leakage occurs, which progresses inflammation further. All of this can create loops in which seizures and inflammation recur with each other. 


\section{Inflammatory Mediators in Epilepsy}

Cytokines are primarily produced by glial cells and neurons during brain inflammation. Sinha et al. [29] supported a theory of cytokine production in the brain triggered by seizure activity. According to this postulation, these proteins stimulate various inflammatory pathways that can lead to nervous system damage and excessive excitability of nerve cells. Vezzani et al. [28] found that induced seizures cause a time-dependent increase of pro-inflammatory cytokines. Sinha et al. [29] observed a high increase in levels of IL-1 $\beta$, IL-2, IL-4, IL-6, IFN- $\gamma$, and TNF- $\alpha$ in serum from patients with epilepsy when compared to the control group. A study by Numis et al. [30] showed that neonates with acute seizures had higher levels of IL-1, IL-6, IL-8, IL-9, IL-13, and TNF- $\alpha$ than neonates without acute seizures.

However, only elevated levels of pro-inflammatory cytokines (IL-1 $\beta$, IL-6, TNF- $\alpha$ ) as well as IL-9 were associated with later development of epilepsy in these children. Upregulation of pro-inflammatory cytokines was present during epileptic activity in rodents [31]. Mice overexpressing the IL-1 receptor antagonist (IL-1Ra) were less susceptible to seizures [28]. Increased IL-1 $\beta$ was detected in the peripheral blood in dogs with epilepsy regardless of the cause [32]. In the CSF of dogs with naturally occurring seizures, significantly higher TNF- $\alpha$ and IL- 6 concentrations were found [33]. In the forebrain of rats, IL- 6 and TNF- $\alpha$ levels were increased after acute seizure, but only briefly, in contrast to IL-1 $\beta$, which did not return to baseline levels even after the seizure had subsided [34]. Concentrations of IL- 6 in the serum of patients with refractory epilepsy were significantly increased compared to healthy people [35]. Moreover, the level of IL-6 was higher in patients receiving polytherapy compared to patients receiving monotherapy. Levels of IL-6 were shown to depend on seizure type. For instance, Il-6 concentration was significantly increased even at the 6-h time point after tonic-clonic seizures compared to simple partial or complex partial seizures [36]. Patients with temporal lobe epilepsy had higher IL-6 serum concentrations than patients with extratemporal lobe epilepsy. Furthermore, it has been demonstrated that lamotrigine remarkably decreases the levels of IL-6, as well as IL-1 $\beta$ [37].

The cytokine CCL2 has been shown to be involved in neurodegenerative diseases such as Alzheimer's disease and multiple sclerosis [38]. CCL2 acts through activation of $\mathrm{G}$ protein-coupled receptors such as the chemokine receptor CCR2. Some AEDs, including topiramate and valproic acid, moderate influx of calcium ions. It has been demonstrated that inflammation induced by lipopolysaccharide administration may increase seizure frequency
[39]. Furthermore, expression of the CCR2 receptor has been found upregulated. Cerri et al. [39] provided evidence that CCL2/CCR2 antagonists suppress lipopolysaccharideinduced seizures. CSF levels of multiple cytokines, including CCL2, were elevated in patients with febrile infectionrelated epilepsy syndrome and febrile status epilepticus [40]. Increased levels of CCL2 and the CCR2 receptor were observed in patients with intractable epilepsy [41].

A study by Wu et al. [42] highlights a crucial role for microRNA miR-206 in epilepsy. Induced expression of miR-206 could alleviate seizures in a kainic acid (KA)-induced epilepsy model. It has been shown that the CXCR2 receptor was also upregulated in patients with temporal lobe epilepsy [43]. The CXCR2-selective antagonist SB225002 could importantly prevent CXCR2 expression.

The chemokine CXCL13 is highly expressed in CNS, and its only specific receptor is CXCR5. Both were found upregulated in the brain tissue of patients with epilepsy and rats with temporal lobe epilepsy. CXCR5 was primarily upregulated in brain cells [44].

TNF- $\alpha$ appears to be clearly involved in the pathogenesis of epilepsy. Mean serum TNF- $\alpha$ levels were significantly increased in patients with febrile seizures [45]. Moreover, TNF- $\alpha$ correlated with seizure recurrence. Another study reported that, in a Theiler's murine encephalomyelitis virus (TMEV)-induced mouse model of limbic epilepsy mRNA, protein levels of TNF- $\alpha$ and TNF- $\alpha$ receptors were significantly upregulated in the hippocampus, a structure critically involved in seizure initiation [46]. TNF- $\alpha$ most likely acts through the TNFR1 receptor, increasing glutamate transmission.

\section{Anti-inflammatory Therapy-a Future Perspective}

One-third of patients with epilepsy do not respond efficiently to AEDs [47]. For this reason, it is important to the development of novel treatments that prevent epileptic seizures or reduce seizure burden. Numerous studies indicate that the activation of a cellular pathway linked to inflammation is a common feature of different types of epilepsy [23,48-50]. The disruption of this cellular mechanism may be a novel potential target for new anti-epileptic therapies. In addition, classical AEDs do not target the reason for epilepsy, but only on its symptoms. Anti-inflammatory drugs may help to target the underlying causes. On the other hand, anti-inflammatory drugs could have unpleasant side effects. 


\section{Conclusion}

Epilepsy is commonly understood to refer to a group of chronic neuronal disorders with a complex and multifactorial background, characterized by recurrent seizures. Results from recent studies increasingly demonstrate that the immune system is an important factor in epileptogenesis. Particular interest has begun to focus on the role of cytokines in this process. Under normal physiological conditions, cytokine expression in the brain has been demonstrated to be relatively low [23, 51]. However, accumulating evidence suggests that it increases during chemically or electrically induced seizures in experimental models and in clinical cases [23, 29, 52]. Additionally, central and peripheral inflammation may play a significant role in the pathogenesis of epilepsy and peripheral inflammatory cytokines may importantly be able to cross the BBB and affect the CNS $[23,39]$. Therefore, a better understanding of the role of the immune system in epilepsy is vital for the development of novel therapeutic perspectives.

Funding This paper was supported by the Medical University of Warsaw (grant number: FW3/2/F/MG/N/20).

\section{Declarations}

Conflict of Interest On behalf of all authors, the corresponding author states that there is no conflict of interest.

Human and Animal Rights and Informed Consent This article does not contain any studies with human or animal subjects performed by any of the authors.

Open Access This article is licensed under a Creative Commons Attribution 4.0 International License, which permits use, sharing, adaptation, distribution and reproduction in any medium or format, as long as you give appropriate credit to the original author(s) and the source, provide a link to the Creative Commons licence, and indicate if changes were made. The images or other third party material in this article are included in the article's Creative Commons licence, unless indicated otherwise in a credit line to the material. If material is not included in the article's Creative Commons licence and your intended use is not permitted by statutory regulation or exceeds the permitted use, you will need to obtain permission directly from the copyright holder. To view a copy of this licence, visit http://creativecommons.org/licenses/by/4.0/.

\section{References}

1. Fisher RS, Acevedo C, Arzimanoglou A, Bogacz A, Cross JH, Elger CE, et al. ILAE official report: a practical clinical definition of epilepsy. Epilepsia. 2014;55(4):475-82. https://doi.org/10. 1111/epi.12550.

2. Helmstaedter C, Witt JA. Epilepsy and cognition - a bidirectional relationship? Seizure. 2017;49:83-9. https://doi.org/10.1016/j. seizure.2017.02.017.
3. Stafstrom CE, Carmant L. Seizures and epilepsy: an overview for neuroscientists. Cold Spring Harb Perspect Med. 2015;5(6): a022426. https://doi.org/10.1101/cshperspect.a022426.

4. Kwan P, Arzimanoglou A, Berg AT, Brodie MJ, Allen Hauser W, Mathern G, et al. Definition of drug resistant epilepsy: consensus proposal by the ad hoc task force of the ILAE commission on therapeutic strategies. Epilepsia. 2010;51(6):1069-77. https://doi. org/10.1111/j.1528-1167.2009.02397.x.

5. Scharfman HE. The neurobiology of epilepsy. Curr Neurol Neurosci Rep. 2007;7(4):348-54. https://doi.org/10.1007/ s11910-007-0053-z.

6. Kurowski P, Grzelka K, Szulczyk P. Ionic mechanism underlying rebound depolarization in medial prefrontal cortex pyramidal neurons. Front Cell Neurosci. 2018;12:93. https://doi.org/10.3389/ fncel.2018.00093.

7. Escayg A, Goldin AL. Sodium channel SCN1A and epilepsy: mutations and mechanisms. Epilepsia. 2010;51(9):1650-8. https:// doi.org/10.1111/j.1528-1167.2010.02640.x.

8. Barker-Haliski M, White SH. Glutamatergic mechanisms associated with seizures and epilepsy. Cold Spring Harb Perspect Med. 2015;5(8): a022863. https://doi.org/10.1101/cshperspect.a022863.

9. Bernard C, Wheal HV. Plasticity of AMPA and NMDA receptormediated epileptiform activity in a chronic model of temporal lobe epilepsy. Epilepsy Res. 1995;21(2):95-107. https://doi.org/ 10.1016/0920-1211(95)00017-5.

10. Dingledine R, Hynes MA, King GL. Involvement of N-methyl-Daspartate receptors in epileptiform bursting in the rat hippocampal slice. J Physiol. 1986;380:175-89. https://doi.org/10.1113/jphys iol.1986.sp016279.

11. Mantegazza M, Curia G, Biagini G, Ragsdale DS, Avoli M. Voltage-gated sodium channels as therapeutic targets in epilepsy and other neurological disorders. Lancet Neurol. 2010;9(4):413-24. https://doi.org/10.1016/S1474-4422(10)70059-4.

12. Sheng J, Liu S, Qin H, Li B, Zhang X. Drug-resistant epilepsy and surgery. Curr Neuropharmacol. 2018;16(1):17-28. https://doi.org/ 10.2174/1570159X15666170504123316.

13. Fisher JL. A mutation in the GABAA receptor $\alpha 1$ subunit linked to human epilepsy affects channel gating properties. Neuropharmacology. 2004;46(5):629-37. https://doi.org/10.1016/j.neuropharm. 2003.11.015.

14. Liao M, Kundap U, Rosch RE, Burrows DRW, Meyer MP, Bencheikh BOA, Cossette P, Samarut É. Targeted knockout of GABA-A receptor gamma 2 subunit provokes transient lightinduced reflex seizures in zebrafish larvae. Dis Model Mech. 2019;12(11):dmm040782. https://doi.org/10.1242/dmm.040782.

15. Rogawski MA, Löscher W, Rho JM. Mechanisms of action of antiseizure drugs and the ketogenic diet. Cold Spring Harb Perspect Med. 2016;6(5): a022780. https://doi.org/10.1101/cshpe rspect.a022780.

16. Löscher W, Rogawski MA. How theories evolved concerning the mechanism of action of barbiturates. Epilepsia. 2012;53(Suppl 8):12-25. https://doi.org/10.1111/epi.12025.

17. Taylor CP, Vartanian MG, Andruszkiewicz R, Silverman RB. 3-alkyl GABA and 3-alkylglutamic acid analogues: two new classes of anticonvulsant agents. Epilepsy Res. 1992;11(2):10310. https://doi.org/10.1016/0920-1211(92)90044-t.

18. Petroff OA, Behar KL, Mattson RH, Rothman DL. Human brain gamma-aminobutyric acid levels and seizure control following initiation of vigabatrin therapy. J Neurochem. 1996;67(6):2399-404. https://doi.org/10.1046/j.1471-4159.1996.67062399.x.

19. Waldmeier PC, Baumann PA, Wicki P, Feldtrauer JJ, Stierlin C, Schmutz M. Similar potency of carbamazepine, oxcarbazepine, and lamotrigine in inhibiting the release of glutamate and other neurotransmitters. Neurology. 1995;45(10):1907-13. https://doi. org/10.1212/wnl.45.10.1907. 
20. Muoio V, Persson PB, Sendeski MM. The neurovascular unit concept review. Acta Physiol (Oxf). 2014;210(4):790-8. https:// doi.org/10.1111/apha.12250.

21 He Y, Zhang H, Yu L, Gunel M, Boggon TJ, Chen H, Min W. Stabilization of VEGFR2 signaling by cerebral cavernous malformation 3 is critical for vascular development. Sci Signal. 2010;3(116):ra26. https://doi.org/10.1126/scisignal.2000722.

22. Ogaki A, Ikegaya Y, Koyama R. Vascular abnormalities and the role of vascular endothelial growth factor in the epileptic brain. Front Pharmacol. 2020;11:20. https://doi.org/10.3389/fphar.2020.00020.

23. Vezzani A, Granata T. Brain inflammation in epilepsy: experimental and clinical evidence. Epilepsia. 2005;46(11):1724-43. https://doi. org/10.1111/j.1528-1167.2005.00298.x.

24. Zlokovic BV. The blood-brain barrier in health and chronic neurodegenerative disorders. Neuron. 2008;57(2):178-201. https://doi. org/10.1016/j.neuron.2008.01.003.

25. Daneman R. The blood-brain barrier in health and disease. Ann Neurol. 2012;72(5):648-72. https://doi.org/10.1002/ana.23648.

26. Vezzani A, Friedman A. Brain inflammation as a biomarker in epilepsy. Biomark Med. 2011;5(5):607-14. https://doi.org/10.2217/ bmm.11.61.

27. Xu D, Miller SD, Koh S. Immune mechanisms in epileptogenesis. Front Cell Neurosci. 2013;7:195. https://doi.org/10.3389/fncel. 2013.00195.

28. Vezzani A, Moneta D, Richichi C, Aliprandi M, Burrows SJ, Ravizza $\mathrm{T}$, et al. Functional role of inflammatory cytokines and antiinflammatory molecules in seizures and epileptogenesis. Epilepsia. 2002;43(Suppl 5):30-5. https://doi.org/10.1046/j.1528-1157. 43.s.5.14.x.

29. Sinha S, Patil SA, Jayalekshmy V, Satishchandra P. Do cytokines have any role in epilepsy? Epilepsy Res. 2008;82(2-3):171-6. https://doi.org/10.1016/j.eplepsyres.2008.07.018.

30. Numis AL, Foster-Barber A, Deng X, Rogers EE, Barkovich AJ, Ferriero DM, et al. Early changes in pro-inflammatory cytokine levels in neonates with encephalopathy are associated with remote epilepsy. Pediatr Res. 2019;86(5):616-21. https://doi.org/10.1038/ s41390-019-0473-x.

31. Youn Y, Sung IK, Lee IG. The role of cytokines in seizures: interleukin (IL)-1 $\beta$, IL-1Ra, IL-8, and IL-10. Korean J Pediatr. 2013;56(7):271-4. https://doi.org/10.3345/kjp.2013.56.7.271.

32. Kostic D, Carlson R, Henke D, Rohn K, Tipold A. Evaluation of IL-1 $\beta$ levels in epilepsy and traumatic brain injury in dogs. BMC Neurosci. 2019;20(1):29. https://doi.org/10.1186/ s12868-019-0509-5.

33. Merbl Y, Sommer A, Chai O, Aroch I, Zimmerman G, Friedman A, et al. Tumor necrosis factor- $\alpha$ and interleukin- 6 concentrations in cerebrospinal fluid of dogs after seizures. J Vet Intern Med. 2014;28(6):1775-81. https://doi.org/10.1111/jvim.12462.

34 Vezzani A, Balosso S, Ravizza T. The role of cytokines in the pathophysiology of epilepsy. Brain Behav Immun. 2008;22(6):797-803. https://doi.org/10.1016/j.bbi.2008.03.009.

35. Ethemoglu O, Ay H, Koyuncu I, Gönel A. Comparison of cytokines and prooxidants/antioxidants markers among adults with refractory versus well-controlled epilepsy: a cross-sectional study. Seizure. 2018;60:105-9. https://doi.org/10.1016/j.seizure. 2018.06.009.

36. Alapirtti T, Lehtimäki K, Nieminen R, Mäkinen R, Raitanen $\mathrm{J}$, Moilanen E, et al. The production of IL- 6 in acute epileptic seizure: a video-EEG study. J Neuroimmunol. 2018;316:50-5. https://doi.org/10.1016/j.jneuroim.2017.12.008.

37. Abu-Rish EY, Dahabiyeh LA, Bustanji Y, Mohamed YS, Browning MJ. Effect of lamotrigine on in vivo and in vitro cytokine secretion in murine model of inflammation. J Neuroimmunol. 2018;322:36-45. https://doi.org/10.1016/j.jneuroim.2018.06.008.
38. Bose S, Cho J. Role of chemokine CCL2 and its receptor CCR2 in neurodegenerative diseases. Arch Pharm Res. 2013;36(9):1039_ 50. https://doi.org/10.1007/s12272-013-0161-z.

39. Cerri C, Genovesi S, Allegra M, Pistillo F, Püntener U, Guglielmotti A, et al. The chemokine CCL2 mediates the seizure-enhancing effects of systemic inflammation. J Neurosci. 2016;36(13):3777-88. https://doi.org/10.1523/JNEUROSCI.0451-15.2016.

40. Kothur K, Bandodkar S, Wienholt L, Chu S, Pope A, Gill D, et al. Etiology is the key determinant of neuroinflammation in epilepsy: elevation of cerebrospinal fluid cytokines and chemokines in febrile infection-related epilepsy syndrome and febrile status epilepticus. Epilepsia. 2019;60(8):1678-88. https://doi.org/10.1111/epi.16275.

41. Wang C, Yang L, Zhang J, Lin Z, Qi J, Duan S. Higher expression of monocyte chemoattractant protein 1 and its receptor in brain tissue of intractable epilepsy patients. J Clin Neurosci. 2016;28:134 40. https://doi.org/10.1016/j.jocn.2015.07.033.

42. Wu Z, Liu Y, Huang J, Huang Y, Fan L. MiR-206 inhibits epilepsy and seizure-induced brain injury by targeting CCL2. Cytotechnology. 2019;71(4):809-18. https://doi.org/10.1007/ s10616-019-00324-3.

43. Xu T, Yu X, Wang T, Liu Y, Liu X, Ou S, et al. The effect of CXCR2 inhibition on seizure activity in the pilocarpine epilepsy mouse model. Brain Res Bull. 2017;134:91-8. https://doi.org/10. 1016/j.brainresbull.2017.07.003.

44. Li R, Ma L, Huang H, Ou S, Yuan J, Xu T, et al. Altered expression of CXCL13 and CXCR5 in intractable temporal lobe epilepsy patients and pilocarpine-induced epileptic rats. Neurochem Res. 2017;42(2):526-40. https://doi.org/10.1007/s11064-016-2102-y.

45. Ha J, Choi J, Kwon A, Kim K, Kim SJ, Bae SH, et al. Interleukin-4 and tumor necrosis factor-alpha levels in children with febrile seizures. Seizure. 2018;58:156-62. https://doi.org/10.1016/j.seizure. 2018.04.004.

46 Patel DC, Wallis G, Dahle EJ, McElroy PB, Thomson KE, Tesi RJ, Szymkowski DE, et al. Hippocampal TNF $\alpha$ signaling contributes to seizure generation in an infection-induced mouse model of limbic epilepsy. eNeuro. 2017;4(2):ENEURO.0105-17.2017. https://doi. org/10.1523/ENEURO.0105-17.2017.

47. Chen Z, Brodie MJ, Liew D, Kwan P. Treatment outcomes in patients with newly diagnosed epilepsy treated with established and new antiepileptic drugs: a 30-year longitudinal cohort study. JAMA Neurol. 2018;75(3):279-86. https://doi.org/10.1001/jaman eurol.2017.3949.

48. Rana A, Musto AE. The role of inflammation in the development of epilepsy. J Neuroinflammation. 2018;15(1):144. https://doi.org/ 10.1186/s12974-018-1192-7.

49. Ekdahl CT, Claasen J-H, Bonde S, Kokaia Z, Lindvall O. Inflammation is detrimental for neurogenesis in adult brain. Proc Natl Acad Sci U S A. 2003;100(23):13632-7. https://doi.org/10.1073/pnas. 2234031100.

50. Jankowsky JL, Patterson PH. The role of cytokines and growth factors in seizures and their sequelae. Prog Neurobiol. 2001;63(2):12549. https://doi.org/10.1016/s0301-0082(00)00022-8.

51 Allan SM, Rothwell NJ. Cytokines and acute neurodegeneration. Nat Rev Neurosci. 2001;2(10):734-44. https://doi.org/10.1038/ 35094583 .

52. Oprica M, Eriksson C, Schultzberg M. Inflammatory mechanisms associated with brain damage induced by kainic acid with special reference to the interleukin-1 system. J Cell Mol Med. 2003;7(2):127-40. https://doi.org/10.1111/j.1582-4934.2003.tb002 11.x.

Publisher's Note Springer Nature remains neutral with regard to jurisdictional claims in published maps and institutional affiliations. 